\title{
Microplastics in Water, Sediments and Macroinvertebrates in a Small River of NW Spain
}

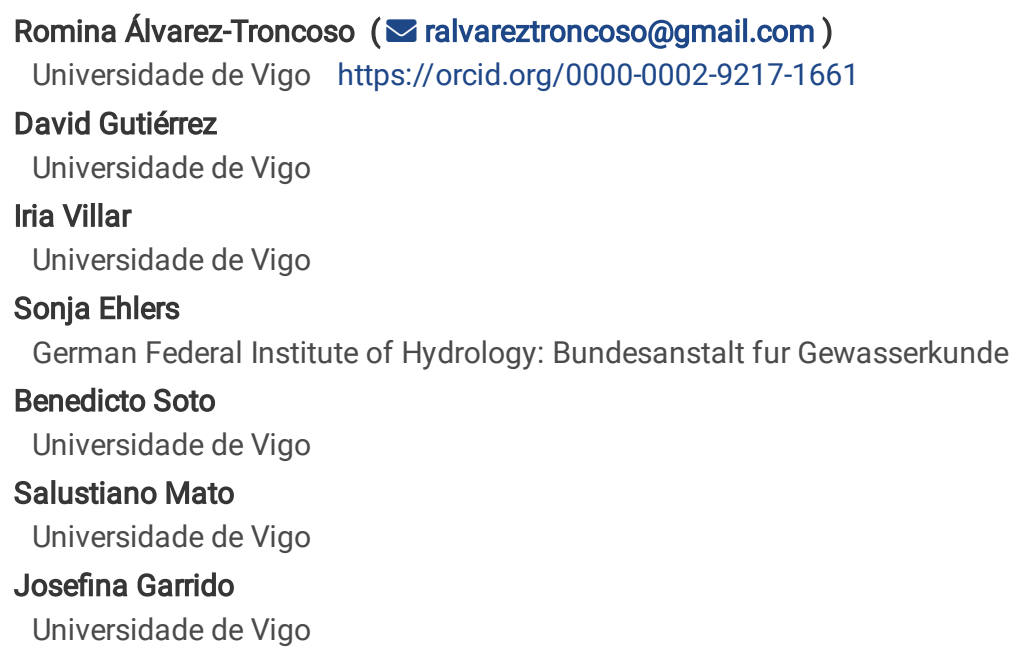

\section{Research Article}

Keywords: Synthetic polymer, Freshwater insect, Microplastics, Plastic pollution, Trichoptera, Odonata

Posted Date: January 31st, 2022

DOI: https://doi.org/10.21203/rs.3.rs-1256371/v1

License: (c) (i) This work is licensed under a Creative Commons Attribution 4.0 International License. Read Full License 


\section{Abstract}

Microplastics (MPs) were sampled in water, sediments and macroinvertebrates in Gafos river (NW Spain) during summer 2020 in three different locations called upstream (G1), upstream of the city (G2) and downstream (G3). Different microplastic (MP) fibers and particles were found in all water samples and in G2 and G3 sediment samples. The analysis of the different types of MPs was carried out by Fourier-transform infrared spectroscopy (FTIR-ATR), Sample Technique: Attenuated Total Reflection (ATR). The majority of them were polyvinyl chloride (PVC) and polyethylene terephthalate (PET). Microplastics were found in the cases of Trichoptera families like Lepidostomatidae and Limnephilidae and inside the body in some Odonatan families such as Gomphidae.

\section{Introduction}

Plastic features (e.g., durability, lightweight) make them one of the most demanded products of our society. Since the 1950s, plastic production has exponentially increased, and nowadays, around 300 million metric tons of this material are manufactured worldwide each year (Scherer et al., 2017, Statista, 2021). Despite the multiple advantages that plastic offers and the massive economic and social benefits that we can obtain from these products, unsuitable resource management has led to litter accumulation in natural ecosystems (Barnes et al., 2009). Plastic particles with a size smaller than $5 \mathrm{~mm}$ are called microplastics (MPs), and can be classified into two groups (Herrera et al., 2018). On the one hand, primary MPs are particles intentionally manufactured with a size $<5 \mathrm{~mm}$, used in resin pellets or as ingredients of a great variety of cosmetic products (Cole et al., 2011; Chang, 2015). On the other hand, secondary MPs originate from disintegrating plastic items (Lambert \& Wagner, 2018).

Similar to other persistent pollutants, microplastics are recognized globally. Their presence was first reported in the ocean in the 1970 s (Carpenter \& Smith, 1972). Nevertheless, some decades ago, research efforts on MP pollution have been oriented towards marine environments (Rochman, 2018). In the last years, this trend has changed, and some studies have shown the presence of these pollutants in both freshwater and terrestrial ecosystems (i.e., Wagner et al., 2014; Rillig \& Lehmann, 2020).

Due to their small size, microplastics can be ingested directly or indirectly by a great variety of animals and can be incorporated and transferred through food webs (Barnes et al., 2009; Setälä et al., 2014). Different studies have tested the exposure of marine and aquatic biota such as freshwater plants, invertebrates, several fish species, and also seabirds and mammals to MPs (Rochman, 2018). In marine organisms, ingestion of large plastic items may cause choking, internal or external wounds, accelerating sores, blocked digestive tract, false sense of satiation, impaired feeding capacity, starvation, debilitation, limited predator avoidance, or death (Gall \& Thompson, 2015; Unger et al., 2017). The impacts caused by MPs are less known, but they are expected to be similar to those mentioned above. For example, the ingestion of microplastics can disrupt physiological processes in marine worms, compromising their ability to store energy (Wright et al., 2013).

Moreover, MPs readily accumulate harmful chemicals such as dichlorodiphenyltrichloroethane (DDT), polychlorinated biphenyls (PCBs), and polybrominated diphenyl ethers (PBDEs) or heavy metals, increasing their concentration by orders of magnitude. This process is reversible, and these pollutants can be released upon ingestion, causing substantial damage in different organisms (Rochman et al., 2014). Regarding freshwater ecosystems, recent studies by Ehlers et al. $(2019,2020)$ found that MPs can be used by different species of caddisflies, which incorporate these particles into their cases. The respective caddisfly larvae build portable cases in which they develop during their larval stage.

The concentration of microplastics in continental waters is highly variable, to the point that only the 20 most polluted rivers in the world transport $67 \%$ of the plastic debris that reaches the oceans each year (Lebreton et al., 2017). Therefore, studies of presence and distribution of MPs in continental waters can help to understand the dynamics of these pollutants in natural ecosystems.

The Galician economy of the study area is closely related to seafood (Salmo trutta and Salmo spec.) production. Therefore, more research efforts should be focused on MP in freshwater environments and potential Salmo prey since MPs were found in several species of commercial interest (Barboza et al., 2018).

\section{Methodology Study area}

To carry out this study, the Gafos River was selected because it is the urban river that crosses the Pontevedra province (Galicia, Spain). This river is included in the Galicia-Costa River basin district. Moreover, it is classified as the Cantabrian -Atlantic coastal river, comprised in the typology 30 (R-T30) (MAGRAMA, 2015). Gafos river flows approximately $10 \mathrm{~km}$ until its mouth in the Pontevedra's sea inlet, forming a basin with $25.57 \mathrm{~km}{ }^{2}$ area that supports a population of around 69,000 inhabitants.

\section{Sample collection}

In summer 2020, a sampling campaign was conducted, and water, sediment and biota samples were collected at G1, G2 and G3 sampling points (Fig. 1). Benthic macroinvertebrate samples were taken according to the methodology established by the Water Framework Directive 
(2000/60/EC) (European Communities, 2000). An aquatic entomological net was used with a mesh of $500 \mu \mathrm{m}$ pore size to collect the macroinvertebrates. Organism samples were pooled and transported to the laboratory in glass bottles with $70 \%$ ethanol. Then, all the individuals were identified up to the family level by using a stereomicroscope and the identification keys of Tachet et al. (2002). With the obtained data, richness, IBMWP index (Iberian Biological Monitoring Working Party) (Alba-Tecedor et al., 2002), IASPT index (IBMWP value divided by the number of families) and richness were calculated to assess the ecological status of the different sampling sites.

Additionally, at each sampling point, several physical and chemical variables were measured in situ using a multiparameter sounding line (Hanna Instruments, Model HI 98194), including water temperature, dissolved oxygen (DO), total dissolved solids (TDS), pH and electrical conductivity (EC). Moreover, water samples were collected in glass bottles to analyse the content of nitrate, nitrite, sulphate, COD (chemical oxygen demand) and TOC (total organic carbon).

For the study of microplastics, three different samples were collected. First, to look for microplastics in the sediments, two methodologies were developed. On the one hand, the sediment from the bed surface that contained the benthic macroinvertebrates (S1) was examined. All the items visually identified as plastic were manually collected and placed into Petri dishes. On the other hand, at each sampling point, two samples of sediment were collected from the shoreline of the rivers with stainless steel rings of $100 \mathrm{~cm}^{3}$ and $5 \mathrm{~cm}$ depth (S2). Finally, for searching microplastics in the water column, the methodology developed by the Libera project (LIBERA, 2020) was followed. In each sampling point, 4L of water was filtered, $2 \mathrm{~L}$ of water from the surface and $2 \mathrm{~L}$ of water from the river's bottom. To filter water samples a manual vacuum pump and nytal-nytex filters Whatman grade 4 with $20 \mu \mathrm{m}$ pore size were used. Immediately afterwards, filters were stored in clean glass containers and transported to the laboratory.

\section{Contamination control}

Based on Ehlers et al., (2022), besides cleaning all the field material like the hand net and sample jars, and all glassware with ultrapure water, we later cleaned the hand net with hypochlorite and then with ultrapure water between each sample site to avoid cross-contamination. We ran blanks to control for contamination of the filtered water. To prevent contamination from synthetic clothing, we wore white cotton lab coats and blue nitrile gloves during sample processing. We did not detect any fibers in the blanks for benthos, for sediments, or for water in samples. However, blue and green fibers were detected in the water column and in the benthos samples.

\section{Water and sediments processing}

In the laboratory, water and sediment samples were analyzed following and adapting the NOAA laboratory methods to analyze microplastics in water and river bed samples (Masura et al., 2015; Rodrigues et al., 2018). For water samples, filters were subjected to wet peroxide oxidation. Hydrogen peroxide (30\%) was added to each filter to remove organic matter. The process was repeated until all the organic matter was removed. Then, the filter content was resuspended and filtered again. The sample was passed through vacuum filtration ( $0.45 \mu \mathrm{m}$ Whatman filters), and all the suspected microplastic materials were deposited on the filter membranes.

On the other side, the wet sediments from each sampling point were first homogenized. After stirring, three $100 \mathrm{~g}$ sub-samples (wet weight) were created from each sampling point and dried at $40^{\circ} \mathrm{C}$ for $48 \mathrm{~h}$ to determine sediment dry weight. The microplastic debris extraction was done following the methodology described by Beibei et al. (2021). Dried sub-samples were placed in $250 \mathrm{~mL}$ glass beakers, and then $50 \mathrm{~mL}$ of hydrogen peroxide (30\%) was added to remove organic matter. This step was repeated until all the organic matter was removed. The room temperature of the laboratory was $20^{\circ} \mathrm{C}$. Then, sub-samples were run through a stacked series of metal sieves ( 5 and $\left.0.055 \mathrm{~mm}\right)$ with Milli-Q $\AA$ water, considering only particles with a size $<5 \mathrm{~mm}$ and $>0.055 \mathrm{~mm}$. Then, a zinc chloride solution $\left(\mathrm{ZnCl}_{2}\right.$; density $\left.1.7 \mathrm{~g} \mathrm{~cm}^{-3}\right)$ was added to separate the remaining high-density mineral fraction from the light fraction, in which microplastics are found. The sub-samples with MPs were again added into $250 \mathrm{~mL}$ beakers with $50 \mathrm{~mL}$ of $\mathrm{ZnCl}_{2}$. Beaker contents were stirred with a magnetic stirrer for 15 min and then samples were kept in an ultrasonic bath for 2 min. Finally, after density separation, the subsample solution was left to settle for at least 2 hours, and the supernatant was filtered, just like with water samples. Filters were dried in an oven at $40^{\circ}$ for 24 hours before microplastic identification.

For MP identification, a stereomicroscope was used. Following the methodology used by Rodrigues et al. (2018), microplastics were classified as fragments, fibers, spheres, sponges and films. In addition, the color of each microplastic particle was noted.

\section{Presence of MPs in fauna}

During the macroinvertebrate identification in the lab, using the stereomicroscope, we detected using the stereomicroscope that in some Odonata bodies (Gomphidae) and Trichoptera cases (Leptoceridae and Limnephilidae) there were incorporated fragments of MPs. The fragments presensent in the bodies or in the cases were of different colors and composition, we detected using the visual identification. We removed those pieces from the organisms using tweezers, labelled them and kept them in Petri dishes. Later these pieces were analyzed in the lab where we conducted FTIR analysis for obtaining more information on polymer types.

\section{FTIR analysis}


We conducted all FTIR measurements with a Nicolet 6700 ATR with a diamond crystal Smart Orbit. The spectral resolution was $4 \mathrm{~cm}^{-1}$ and measurements were conducted in a wavenumber range of $4000-400 \mathrm{~cm}^{-1}$.

\section{Results}

\section{Water quality and macroinvertebrate community}

Figure 2 shows the abundance of the different identified taxa. In total, 566 individuals were captured between the three sampling points. Independent of the site, insects were the most abundant group. In G1, specimens belonging to Diptera were the most abundant order, followed by Odonata and Coleoptera. Nevertheless, in the second sampling point (G2), Trichoptera were the most abundant individuals, followed by Coleoptera and, to a lesser extent, molluscs. Dipterans were again the most abundant group in the last sampling point, followed by Mollusca.

Table 1 shows the result of the Indexes calculated to assess the water quality. IBMWP index indicates that the Gafos River in sites G1 and G2 is in a good ecological state. In fact, in the high and medium course, Gafos River reached the top water quality category (Good/Moderate). Also, in these points, the water has a good chemical quality (Table 2).

Table 1

Value of the indexes calculated to evaluate the ecological status of water at the different sampling points in Gafos river.

\begin{tabular}{|cccccl|}
\hline Site & \multicolumn{2}{c}{ Richness } & IBMWP & RSS & \multicolumn{2}{c|}{ IASPT } & \multicolumn{1}{c|}{ Ecological Status } \\
\hline G1 & 26 & 146 & 0.65 & 5.6 & Good/Moderate \\
\hline G2 & 28 & 168 & 0.75 & 6.0 & Good/Moderate \\
G3 & 14 & 62 & 0.28 & 4.4 & Poor/Bad \\
\hline
\end{tabular}

Table 2

Chemical characteristics of water in each sampling points.

\begin{tabular}{|c|c|c|c|c|c|c|c|c|c|c|c|c|}
\hline Site & $\mathrm{pH}$ & $\begin{array}{l}\mathrm{EC} \\
(\mu \mathrm{S} / \mathrm{cm})\end{array}$ & $\begin{array}{l}\text { DO } \\
(\mathrm{mg} / \mathrm{L})\end{array}$ & $\begin{array}{l}\text { Temperature } \\
\left({ }^{\circ} \mathrm{C}\right)\end{array}$ & $\begin{array}{l}\text { TDS } \\
\text { (mg/L) }\end{array}$ & $\begin{array}{l}\text { Chloride } \\
\text { (mg/L) }\end{array}$ & $\begin{array}{l}\text { Nitrite } \\
\text { (mg/L) }\end{array}$ & $\begin{array}{l}\text { Nitrate } \\
(\mathrm{mg} / \mathrm{L})\end{array}$ & $\begin{array}{l}\text { Phosphate } \\
\text { (mg/L) }\end{array}$ & $\begin{array}{l}\text { Sulphate } \\
\text { (mg/L) }\end{array}$ & $\begin{array}{l}\mathrm{DQO} \\
\left(\mathrm{mgO}_{2} / \mathrm{L}\right)\end{array}$ & $\begin{array}{l}\text { TOC } \\
\text { (mg/L) }\end{array}$ \\
\hline G1 & 5.9 & 188 & 18.8 & 17.3 & 94 & 15.45 & $<0.05$ & 4.98 & $<0.05$ & 6.92 & 4.0 & 1.82 \\
\hline G2 & 6.0 & 224 & 13.4 & 18.8 & 112 & 15.35 & $<0.05$ & 5.42 & $<0.05$ & 8.32 & 0.8 & 2.16 \\
\hline G3 & 7.1 & 487 & 6.6 & 18.8 & 142 & 15.7 & $<0.05$ & 4.99 & $<0.05$ & 7.05 & 13.6 & 2.55 \\
\hline
\end{tabular}

Nevertheless, after crossing the city of Pontevedra, the index value decreased to the point that, close to the mouth (G3), water quality was classified as poor/bad. In the same vein as the IBMWP, the richness index reached the highest value at sampling points G1 and G2. The poor water quality in $\mathrm{G} 3$ is also reflected by a poor diversity, shown by the low number of different taxa. Finally, IASPT also supports the results shown by the IBMWP index.

\section{Microplastics in the sediment from the bed surface sediments}

During the processing of the macroinvertebrate samples, 34 particles were visually identified as plastic debris. Figure 3 shows the abundance of the different polymers found in the Gafos River. Polyester (PEST) was the most abundant polymer independent of the sampling site, followed by Polyethylene (PE) and Polyethylenerephthalate (PET; which is a polyester) in G1 and G2. For differentiating PET from other PEST we observed peaks at the wavenumbers 1722, 1597, 1251, 1115, 1066, and specifically the peaks among 738 and $704 \mathrm{~cm}^{-1}$ (Pandey et al, 2016). For PET the wave number range found was 1714, 1241, 1095, 873 and $724 \mathrm{~cm}^{-1}$ (Pereira et al, 2017). Also, the wavenumbers 1712, 1409, 1340,1244, 1095, $1017,872,847$ and $722 \mathrm{~cm}^{-1}$ show the presence of polyethylene terephthalate (PET) (Jung et al. 2018).

At the G3 sampling point, Polyvinyl chloride (PVC) and Polypropylene (PP) were more abundant than at the other points. For characterizing PVC, the wave number range that it is analyzed is the rank between $600-750 \mathrm{~cm}^{-1}$ (D'Amelia et al, 2016). For the G3 sampling the results showed that the values were in that rank.

\section{Microplastics in the water column and S2 sediments}

Figure 4 shows the MPs extracted from sediments (S2) and water samples. On the one hand, in sediment samples 28 MPs were found: 19 in G2 point and 9 in G3. No microplastic was found at point G1. On the other hand, in water samples, MPs were detected at all three studied points. G2 was the point with the highest abundance of MPs (19), followed by G1 (12) and G3 (2) to a lesser extent. All the microplastics collected in this study were fibers and fragments of 4 different colors (Fig. 5). 
Fibers were more abundant than fragments in all studied samples, with the exception of sediments in G2. Moreover, the most frequent color was blue, followed by black and red.

\section{Microplastics in the Gomphidae body and Trichoptera cases}

The polymers found in Gomphus were ethylene-vinyl- acetate and polyesterurethane particles with the shape of balls. In the Trichoptera cases the polyethylene was found as a small piece of $50 \mathrm{~mm}$.

Figure 6 shows the graphic with the wavenumbers of the FTIR spectra representing the presence of PEST in the Odonata sample. The red arrows show the wavenumbers related to the polymeric read. For complementing this, the figure 7 shows the body of a Gomphus with the presence of ethylene-vinyl- acetate and polyesterurethane particles inside. In addition, figure 8 shows the pieces of MPs present in the Trichoptera cases that were identified as polyethylene.

\section{Discussion}

The results that were obtained related to the water quality indicate that the Gafos river is in an excellent ecological state in G1 and G2 points. After crossing the city of Pontevedra and the industrial area located in the suburbs (G3 point), the river suffers a degradation process that reduces the water quality, assessed by the IBMWP and the IASPT indexes. This fact is also supported by the richness values calculated for each point. The highest richness values were reached in $\mathrm{G} 1$ and $\mathrm{G} 2$ (Table 1), while in $\mathrm{G} 3$, the diversity of taxa was much smaller than in the sites located upstream. The biodiversity in rivers is one of the most commonly used indicators for different disturbances (Strayer \& Dudgeon, 2010). In this study, as can be seen in Fig. 1, the Gafos river flows mostly through agricultural areas until it reaches the city of Pontevedra. The impact of agriculture and the increase in organic pollution might explain the high abundance of chironomids found in G3 (Fig. 2), which could be a consequence of an increase in the nutrient content from these crop zones, or by the higher levels of organic matter found in G3 (Marziali et al., 2010).

The MP concentration found was similar to the findings reported by other authors at different sites worldwide (Table 3 ). Regarding polymer types, PE and PP are the most abundant polymers in river sediments. Previous studies support our findings (Cole et al., 2011; Dris et al., 2016; Rodrigues et al., 2018), explaining that these low-density polymers are likely to be transported longer distances, while plastics with a high density like PET or PSA would likely accumulate close to the source points (Beibei He et al., 2021).

Table 3

The microplastic concentration found in sediments and the water column in different studies including this one.

\begin{tabular}{|llll|}
\hline No & Location & Concentration & Reference \\
\hline 1 & Hudson River, USA & 0.98 particles/liter surface water & Miller et al. (2017) \\
\hline 2 & River Thames, UK & 66 particles per $100 \mathrm{~g}$ of dry sediment & Horton et al. (2017) \\
\hline 3 & Shangai River, China & $80.2 \pm 59.4$ particles per $100 \mathrm{~g}$ of dry sediments & Peng et al. (2018) \\
\hline 4 & Changjiang Estuary, China & $12.1 \pm 0.9$ particles per $100 \mathrm{~g}$ of dry sediment & Peng et al. (2017) \\
\hline 5 & Ciwalengke River, Indonesia & $5.85 \pm 3.28$ particles per liter & Chaya Alam et al. (2019) \\
\hline 6 & Ciwalengke River, Indonesia & $3.03 \pm 1.59$ particles per 100 g of dry sediment & Chaya Alam et al. (2019) \\
\hline 7 & Antigua River, Portugal & $18-629$ particles per kg of dry sediment & Rodrigues et al. (2018) \\
\hline 8 & Gafos river, Spain & $0-83.27$ particles per kg of dry sediment & This study \\
\hline 9 & Gafos river, Spain & $0-4.75$ particles per liter & This study \\
\hline
\end{tabular}

Polyester and, more specifically, PET fibers represent the most significant volume of synthetic fibers produced worldwide. These materials are produced in higher quantities than any other natural or synthetic fiber (Jaffe et al., 2020). Moreover, PET is one of the most frequently produced thermoplastics, and their primary use is for manufacturing single-use products like beverage bottles, plastic food packaging films, or containers. Although waste-derived materials can be recycled, less than half of the total products are recovered, and the remaining accumulate in natural environments (Kawai et al., 2020). The more urbanized area around Gafos would explain that the most abundant polymerin the Gafos river was PEST, and more specifically PET (Fig. 3).

Regarding the morphology of the particles, independent from the sampling point, fibers were the most abundant type, similar to the findings by Rodrigues et al. (2018) and Hübner et al. (2020). These pollutants are released during the washing process. If domestic water treatment is not sufficient in wastewater treatment plants, fibers can reach rivers, where they then end up in the water column (Fig. 4) (Browne et al., 2011). Another main entry route of microplastics into freshwater ecosystems is the runoff produced in riverbanks, which accumulates the garbage in the banks that later will be carried into the river. For instance, Rodrigues et al. (2018) found higher microplastic levels in the Antigua river's sediments 
after rainfall and wind periods due to the intense surface runoff. It is crucial to analyze if there are differences in microplastic levels among dry seasons and wet seasons in future studies.

Regarding the colors of the different particles, blue microplastics were the most frequent, followed by black and red. These results are in line with the findings of other studies like Zhang et al. (2019) and Yan et al. (2019). Nevertheless, there is evidence that the ingestion is not the only problem associated with the presence of MPs in aquatic environments (Ehlers et al. (2019)) found MP particles in caddisfly cases, and their results showed that the microplastic particles incorporated into the caddisfly cases also showed a wide spectrum of colors.

In this study, MPs were also detected in the cases of different trichopteran and in the bodies of odonatan species (Fig. 6-8). This is one of the first times that the presence of microplastics in the biological construction of freshwater organisms has been shown (Ehlers et al. (2019); Galliteli et al. (2020) and Galliteli et at (2021). Microplastics can act as a vector for persistent organic pollutants and toxic leachates. When these plastic particles are incorporated into the cases, the proximity to the larval body may be harmful for caddisfly larvae (Ehlers et al., 2019). Another recent study showed that PVC and PET particle content in the cases might threaten caddisflies by destabilizing these cases. This change in the stability of the cases reduces the protective function of the cases and presumably increases the animals' predation risk (Ehlers et al., 2020). Moreover, as plastic is lighter than sand, larvae may be positively buoyant and could be carried away by currents. Both effects could limit the survival of caddisflies, which are critical primary consumers in aquatic ecosystems (Ehlers et al., 2020).

Microplastics in freshwater fauna, either as part of biological structures or inside the digestive tract upon ingestion, represent a risk for global freshwater ecosystems (Kumar et al, 2021). There are many studies focusing on MP transport through the food web in marine environments (Horn et al., 2019; Schmid et al., 2021). However, such studies in freshwater ecosystems are mostly lacking. Nevertheless, some authors have studied the transport of microplastics through the aquatic food web. D'Souza et al. (2019) found high microplastic concentrations in the fecal and regurgitated pellets from Eurasian dippers (Cinclus cinclus). This study found that plastics were present in both adult and nestling diets, showing trophic transfer of plastics from invertebrate prey to apex predators. Furthermore, this study demonstrated the intergenerational transport of plastics in prey provisioned from parents to nest-bound offspring.

The bioaccumulation and biomagnification processes of microplastics through the food web are well known (Miller et al, 2020; Carbery et al., 2018). As part of the food web, humans are also affected by these pollutants since we represent the upper apical predator. The uptake of plastic particles by humans occurs through terrestrial and aquatic food products, drinking water, and inhalation (Carbery et al., 2018; Vethaak and Lestie, 2016). For example, seafood may be contaminated with microplastics through ingestion of natural prey or adherence to the organism's surface (Kolandhasamy et al. 2018). The risk is more prominent with animals eaten in whole. For instance, Van Cauwenberghe and Janssen (2014) showed that the blue mussel Mytilus edulis contained on average $0.36 \pm 0.07 \mathrm{MP}$ particles $\mathrm{g}^{-1}$. Some studies have demonstrated the translocation of polystyrene and PVC particles from the gut cavity to the lymph and circulatory system of the marine mussel, Mytilus edulis (L.). Tiny particles (<30 nm) have the potential to cross cell membranes, the blood-brain barrier, and the placenta, with adverse effects like oxidative stress, cell damage, inflammation, and impairment of energy allocation (Hussain et al, 2001).

\section{Conclusions}

Microplastics were detected in water, sediments and organisms of a small river in northwestern Spain and their concentration increased as human activity increased.

The examined caddisflies can incorporate microplastics into their cases during the larval stage. Hence, these animals could be used as bioindicators for microplastic pollution (Ehlers et al., 2019).

On the other hand, the ecological quality indices of rivers do not provide information on the presence of microplastics. Therefore, future research should consider the possible inclusion of these emerging pollutants in the indexes of freshwater quality.

More studies are needed to establish a standardized methodology for studying microplastics in freshwater ecosystems. We conclude that based on the limited number of high-quality studies identified, standardization of microplastic analysis in aquatic fauna is needed, as we found in caddisfly larval cases and other groups (Odonata), these groups might have the potential to be used as bioindicators. Despite the quality limitations, our analysis confirmed that microplastic is frequently present in freshwaters aquatic invertebrates. More studies are needed to better understand selection, occurrence, shape, polymer types, and particle sizes, particularly for the small plastic particles inside the macroinvertebrates and as part of the benthos.

\section{Declarations}

\section{ACKNOWLEDGEMENTS}

This research received a specific grant from the Deputation of Pontevedra (Spain) from the funding agency. 
All authors agreed with the content and that all gave explicit consent to submit and that they obtained consent from the responsible authorities at the University of Vigo (Spain) and University of Koblenz-Landau, Koblenz, Germany, in where the work has been carried out, before the work is submitted.

All authors contributed to the study conception and design. Material preparation, data collection and analysis were performed by Romina ÁlvarezTroncoso, David Gutiérrez, Iria Villar, Sonja. M. Ehlers, Benedicto Soto, Salustiano Mato and Josefina Garrido. The first draft of the manuscript was written by Romina Álvarez-Troncoso and David Gutiérrez and all authors commented on previous versions of the manuscript. All authors read and approved the final manuscript.

\section{COMPETING INTERESTS}

The authors declare that they have no conflict of interest.

\section{References}

1. Alba-Tercedor J, Jáimez-Cuéllar P, Álvarez M, Avilés J, Bonada N, Casas J et al (2002) Caracterización del estado ecológico de ríos mediterráneos ibéricos mediante el índice IBMWP (antes BMWP'). Limnetica 21(2):175-185

2. Barboza LGA, Vethaak AD, Lavorante BR, Lundebye AK, Guilhermino L (2018) Marine Microplastic Debris: An Emerging Issue for Food Security, Food Safety and Human Health. Marine Pollution Bulletin 133(348):336. DOI: 10.1016/j.marpolbul.2018.05.047

3. Barnes DK, Galgani F, Thompson RC, Barlaz M (2009) Accumulation and fragmentation of plastic debris in global environments. Philosophical Transactions of the Royal Society Biological 364:1985-1998. http://dx.doi.org/10.1098/rstb.2008.0205

4. Beibei He M, Smith P, Egodawatta GA, Ayoko L, Rintoul AG (2021) Dispersal and transport of microplastics in river sediments. Environ Pollut. 279, 116884, ISSN 0269-7491 https://doi.org/10.1016/j.envpol.2021.116884

5. Browne MA, Crump P, Niven SJ, Teuten E, Tonkin A, Galloway TS et al (2011) Accumulation of microplastic on shorelines worldwide: Sources and sinks. Environ Sci Technol 45:9175-9179

6. Carpenter EJ, Smith KL (1972) Plastics on the sargasso sea surface. Science 175:1240-1241

7. Carbery M, O'Connor W, Palanisami T (2018) Trophic transfer of microplastics and mixed contaminants in the marine food web and implications for human health. Environment International 115:400-409. doi:10.1016/j.envint.2018.03. 007. PMID:29653694

8. Chang M (2015) Reducing microplastics from facial exfoliating cleansers in wastewater through treatment versus consumer product decisions. Mar Pollut Bull 101(1):330-333

9. Council of the European Communities (2000) Directive 2000/60/EC of the European Parliament and Council of Benetti, 20 October 2000 establishing a framework for community 19 action in the field of water policy. Official Journal of the European Communities L327:72

10. D’Amelia R, Gentile S, Nirode W, Huang L (2016) Quantitative Analysis of Copolymers and Blends of Polyvinyl Acetate (PVAc) Using Fourier Transform Infrared Spectroscopy (FTIR) and Elemental Analysis (EA). World Journal of Chemical Education 4:25-31. 10.12691/wjce-4-2-1

11. Ehlers S, Manz W (2019) Microplastics of different characteristics are incorporated into the larval cases of the freshwater caddisfly Lepidostoma basale. Aquatic Biology. 10.3354/ab00711

12. Ehlers SM, AI Najjar T, Taupp T, Koop JHE (2020) PVC and PET microplastics in caddisfly (Lepidostoma basale) cases reduce case stability. Environ Sci Pollut Res 27:22380-22389. https://doi.org/10.1007/s11356-020-08790-5

13. Ehlers SM, Julius A, Ellrich, Jochen HE, Koop (2022) Microplastic load and polymer type composition in European rocky intertidal snails: Consistency across locations, wave exposure and years. Environmental Pollution,Volume 292, Part A, 118280. 0269-7491. https://doi.org/10.1016/j.envpol.2021.118280

14. España RD (2015) 817/ de 11 de septiembre, por el que se establecen los criterios de seguimiento y evaluación del estado de las aguas superficiales y las normas de calidad ambiental.Boletín Oficial del Estado, 11 de Septiembre de 2015, num 219.

15. Gallitelli L, Cera A, Cesarini G, Pietrelli L, Scalici M (2021) Preliminary indoor evidences of microplastic effects on freshwater benthic macroinvertebrates. Sci Rep 11(1):720. doi:10.1038/s41598-020-80606-5

16. Gallitelli L, Cesarini G, Cera A, Sighicelli M, Lecce F, Menegoni P, Scalici M (2020) Transport and Deposition of Microplastics and Mesoplastics along the River Course: A Case Study of a Small River in Central Italy. Hydrology 7(4). doi:10.3390/hydrology7040090

17. Herrera A, Garrido-Amador P, Martínez I, Samper MD, López-Martínez J (2018) Novel methodology to isolate microplastics from vegetal-rich samples. Mar Pollut Bull 129(1):61-69

18. Hübner MK, Michler-Kozma DN, Gabel F (2020) Microplastic concentrations at the water surface are reduced by decreasing flow velocities caused by a reservoir. Fundaments of Applied Limnology 194/1:49-56

19. Hussain N, Jaitley V, Florence AT (2001) Recent advances in the understanding of uptake of microparticulates across the gastrointestinal lymphatics. Adv Drug Deliv Rev 50:107-142

Page $7 / 12$ 
20. Kasirajan S, Ngouajio M (2012) Polyethylene and biodegradable mulches for agricultural applications: a review. Agronomy for Sustainable Development 32:501-529. https://doi.org/10.1007/s13593-011-0068-3

21. Kolandhasamy P, Lei Su J, Li X, Qu K, Jabeen H, Shi (2018) Adherence of microplastics to soft tissue of mussels: A novel way to uptake microplastics beyond ingestion. Science of The Total Environment Volumes. 610-611, Pages 635-640, ISSN 0048-9697 https://doi.org/10.1016/j.scitotenv.2017.08.053

22. Kumar R, Sharma P, Manna C (2021) Abundance, interaction, ingestion, ecological concerns, and mitigation policies of microplastic pollution in riverine ecosystem: A review, Science of The Total Environment, Volume 782, 146695. 0048-9697.

https://doi.org/10.1016/j.scitotenv.2021.146695. Monika Jain

23. Lambert S, Wagner M (2018) Microplastics Are Contaminants of Emerging Concern in Freshwater Environments: An Overview. In: Wagner M, Lambert S (eds) Freshwater Microplastics. The Handbook of Environmental Chemistry, vol 58. Springer, Cham. https://doi.org/10.1007/9783-319-61615-5_1

24. Lebreton L, van der Zwet J, Damsteeg JW et al (2017) River plastic emissions to the world's oceans. Nat Commun 8:15611. https://doi.org/10.1038/ncomms15611

25. LIBERA (2019) Protocolo de muestreo e identificación de microplásticos en ríos (HyT - LIBERA). 68pp

26. MAGRAMA (2011) Protocolo de muestreo y laboratorio de fauna bentónica de invertebrados vadeables. Cód: ML-Rvl-2011. 23 pp. Ministerio de Agricultura y Medio Ambiente. Spanish Goverment

27. MAGRAMA (2015) Real Decreto 817/2015, de 11 de septiembre, por el que se establecen los criterios de seguimiento y evaluación del estado de las aguas superficiales y las normas de calidad ambiental. Ministerio de Agricultura y Medio Ambiente. Spanish Goverment

28. Melissa R, Jung FD, Horgen SV, Orski, Viviana Rodriguez C, Kathryn L, Beers, George H, Balazs T, Todd Jones TM, Work KC, Brignac S-J, Royer KD, Hyrenbach BA, Jensen JM, Lynch (2018) Validation of ATR FT-IR to identify polymers of plastic marine debris, including those ingested by marine organisms, Marine Pollution Bulletin, Volume 127,Pages 704-716, ISSN 0025-326X, https://doi.org/10.1016/j.marpolbul.2017.12.061

29. Miller ME, Hamann M, Kroon FJ (2020) Bioaccumulation and biomagnification of microplastics in marine organisms: A review and metaanalysis of current data. PLoS ONE 15(10):e0240792. https://doi.org/10.1371/journal.pone.0240792

30. Ory NC, Sobral P, Ferreira JL, Thiel M (2017) Amberstripe scad Decapterus muroadsi (Carangidae) fish ingest blue microplastics resembling their copepod prey along the coast of Rapa Nui (Easter Island) in the South Pacific subtropical gyre. Science of The Total Environment, Volume 586, 2017, Pages 430-437, ISSN 0048-9697, https://doi.org/10.1016/j.scitotenv.2017.01.175

31. Pandey M, Joshi G, Mukherjee, Amitava, Thomas, Paramanandam (2016) Electrical properties and thermal degradation of poly(vinyl chloride)/polyvinylidene fluoride/ZnO polymer nanocomposites. Polymer International

32. Pereira AP, Silva M, Paula A, Tommasini F (2017) Processing and Characterization of PET Composites Reinforced With Geopolymer Concrete Waste. Materials Research. 10.1590/1980-5373-mr-2017-0734

33. Rillig MC, Lehmann A (2020) Microplastic in terrestrial ecosystems. Science 368(6498):1430-1431

34. Rochman CM, Kurobe T, Flores I, Teh SJ (2014) Early warning signs of endocrine disruption in adult fish from the ingestion of polyethylene with and without sorbed chemical pollutants from the marine environment. Sci Total Environ 493:656-661

35. Rochman CM (2018) Microplastics research-from sink to source. Science 360(6384):28-29

36. Rodrigues MO, Abrantes N, Gonçalves FJM, Nogueira H, Marques JC, Gonçalves AMM (2018) Spatial and temporal distribution of microplastics in water and sediments of a freshwater system (Antuã River, Portugal). Science of The Total Environment. Aug 15;633:15491559. doi: 10.1016/j.scitotenv.2018.03.233. Epub 2018 Apr 4. PMID: 29758905

37. Scherer C, Brennholt N, Reifferscheid G, Wagner M (2017) Feeding type and development drive the ingestion of microplastics by freshwater invertebrates. Sci Rep 7(1):1-9

38. Setälä O, Fleming-Lehtinen V, Lehtiniemi M (2014) Ingestion and transfer of microplastics in the planktonic food web. Environmental Pollution 185:77-83. http://dx.doi.org/ 10.1016/j.envpol.2013.10.013

39. Tachet H, Richoux P, Bournaud M, Usseglio-polatera P (2002) Invertebrés d’Eau Douce (2nd corrected impression). CNRS editions. Paris. France. $588 \mathrm{pp}$

40. Unger B, Herr H, Benke H, Böhmert M, Burkhardt-Holm P, Dähne M, Hillmann M, Wolff-Schmidt K, Wohlsein P, Siebert U (2017) Marine debris in harbour porpoises and seals from German waters Marine Environmental Research, Volume 130. 77-84.

https://doi.org/10.1016/j.marenvres.2017.07.009

41. Wagner M, Scherer C, Alvarez-Muñoz D et al (2014) Microplastics in freshwater ecosystems: what we know and what we need to know. Environ Sci Eur 26:12. https://doi.org/10.1186/s12302-014-0012-7

42. Wright SL, Rowe D, Thompson RC, Galloway TS (2013) Microplastic ingestion decreases energy reserves in marine worms. Curr Biol 23(23):1031-1033

43. Web References (2021) : Global plastic production 1950-2019 | Statista. Retrieved 31 March 2021, from https://www.statista.com/statistics/ 
Figures

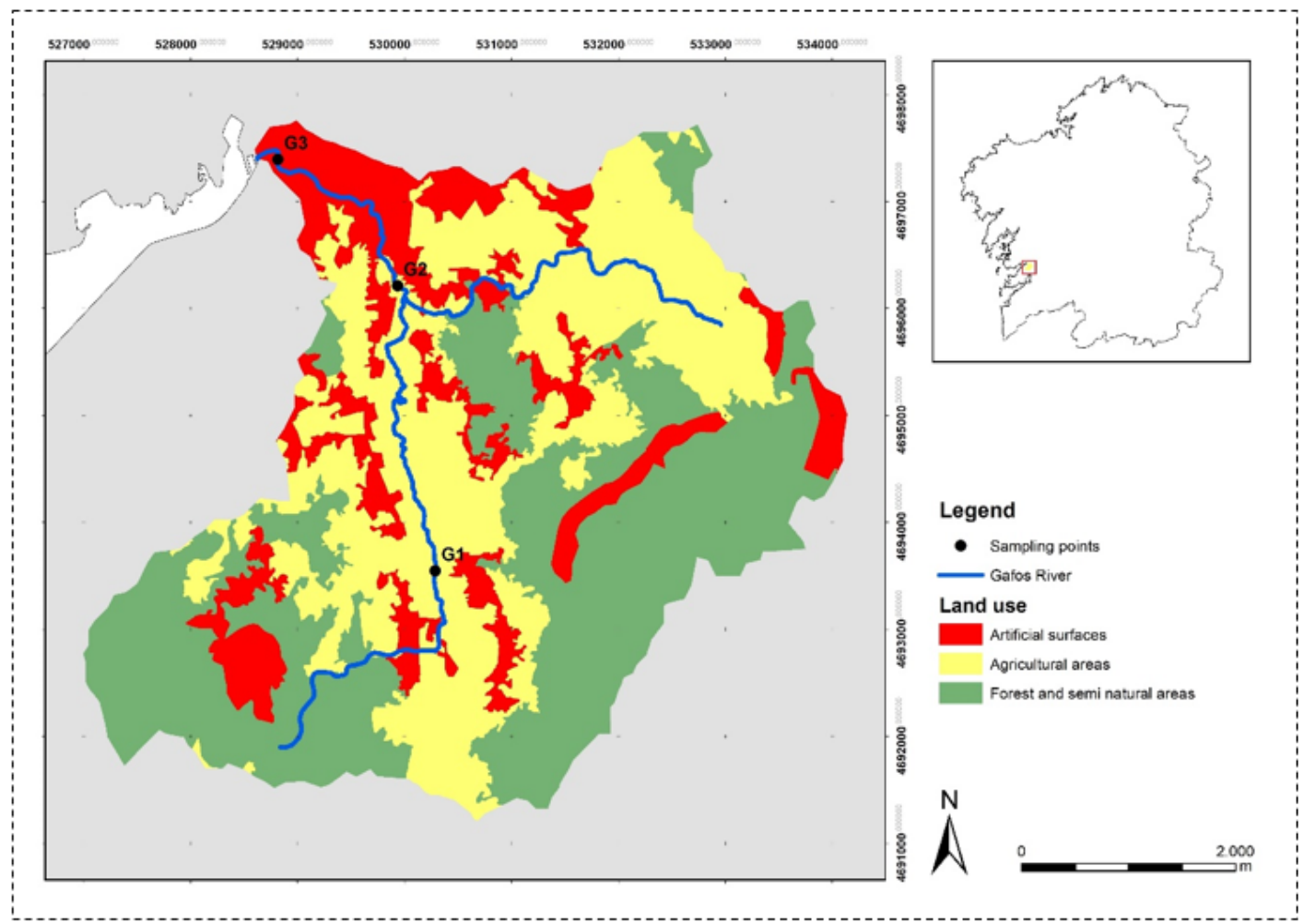

\section{Figure 1}

Watershed of Gafos river and sampling points (G1, G2 and G3).

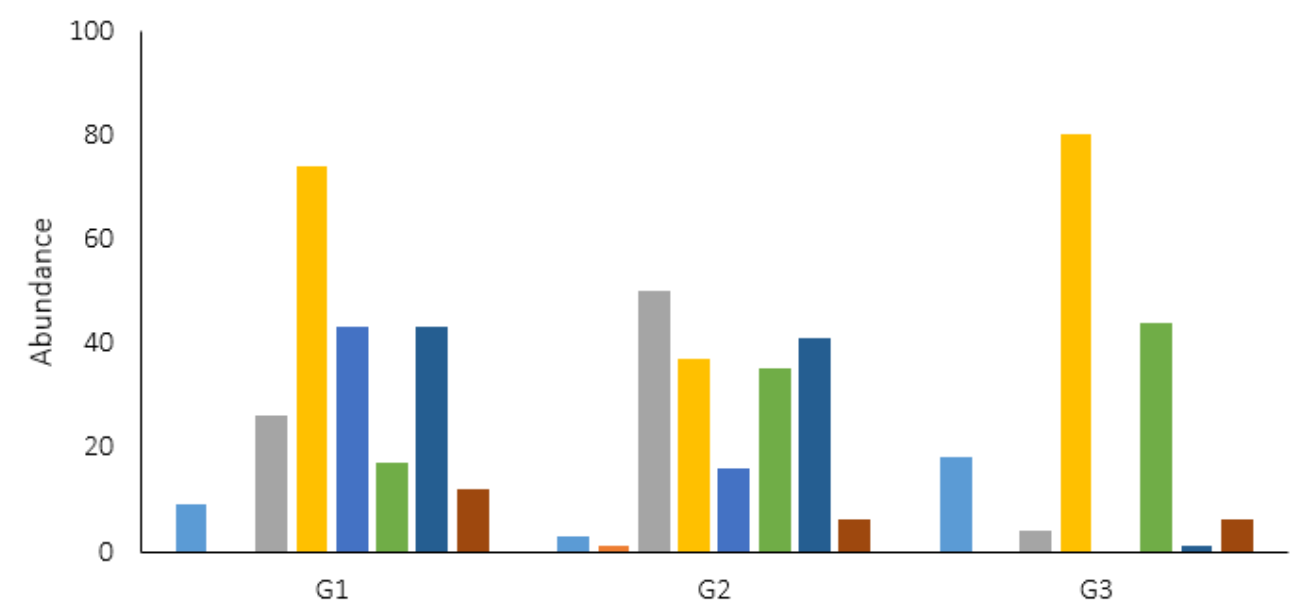

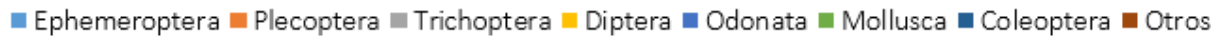

\section{Figure 2}

Abundance of the different macroinvertebrate taxa captured in each sampling point. 


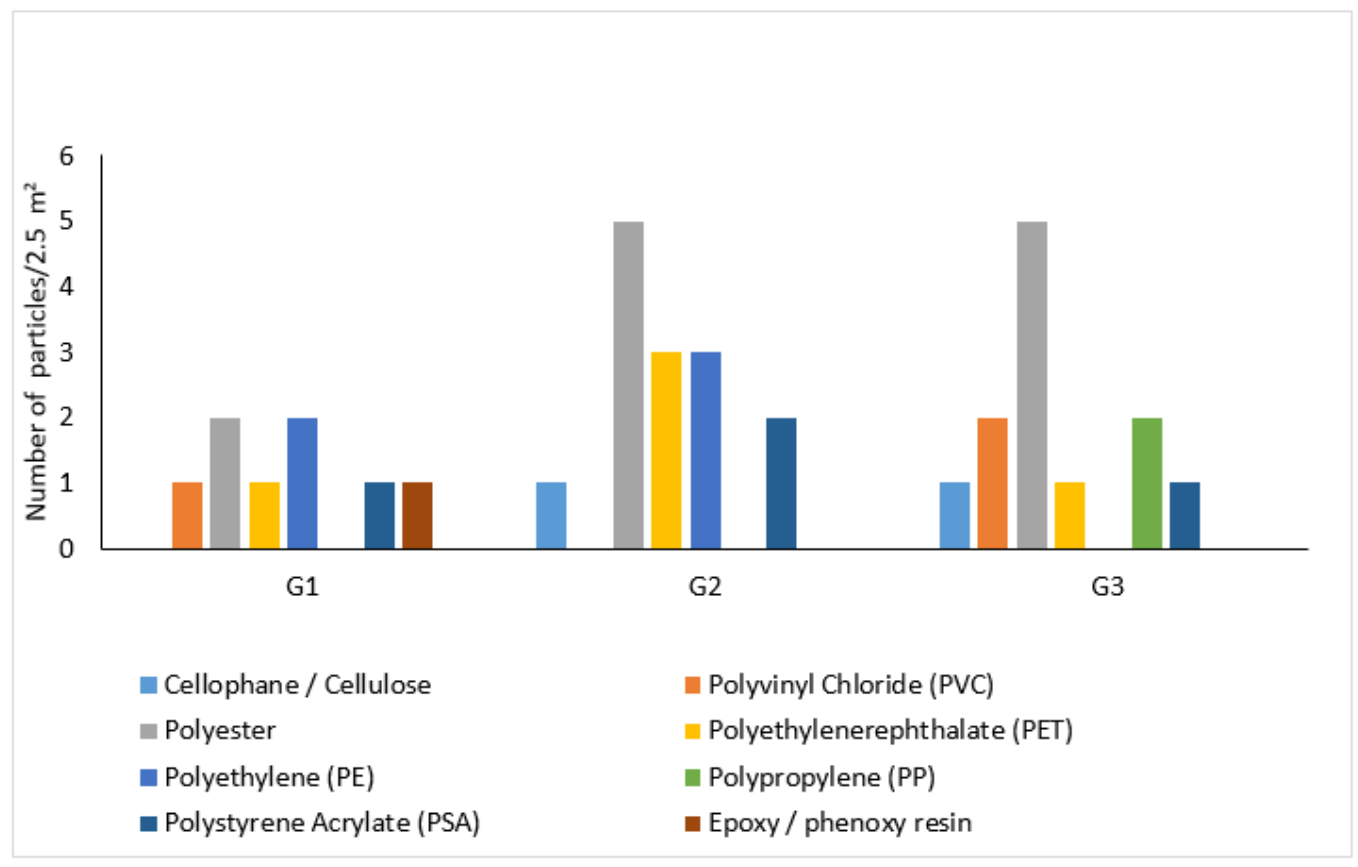

\section{Figure 3}

Abundance of the different polymers found in sediments from bed surface (S1) in G1, G2 and G3 sampling points.

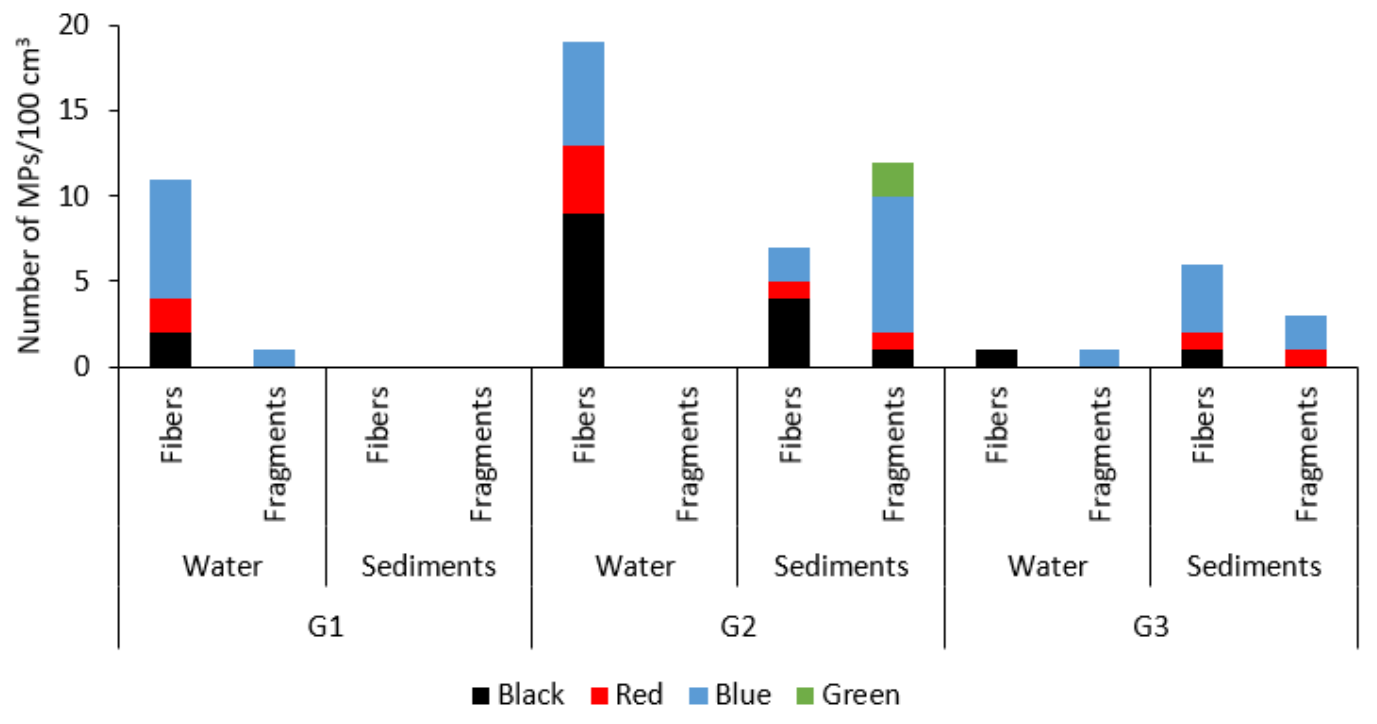

\section{Figure 4}

Abundance of microplastics (MPs) according to morphology and color found in water and sediments from each sampling point. 

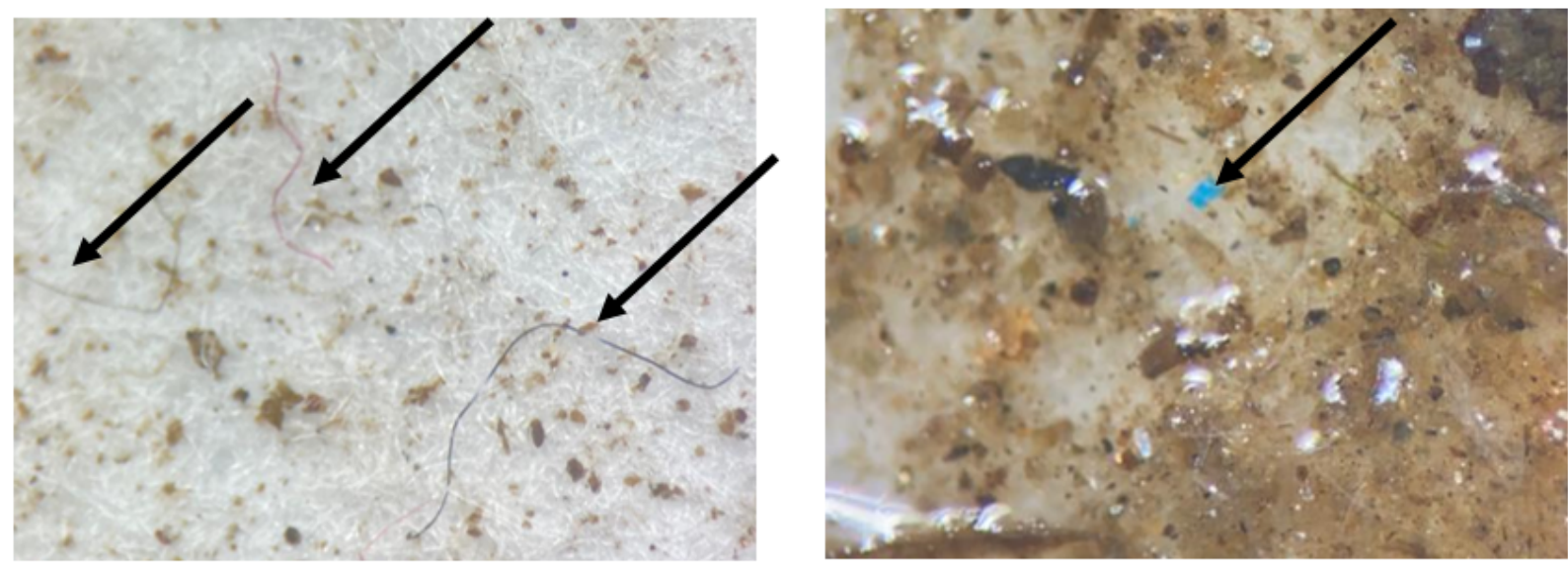

\section{Figure 5}

Different microplastic typologies in Gafos river were identified under a stereoscopic microscope: fiber on the left and blue fragment on the right.

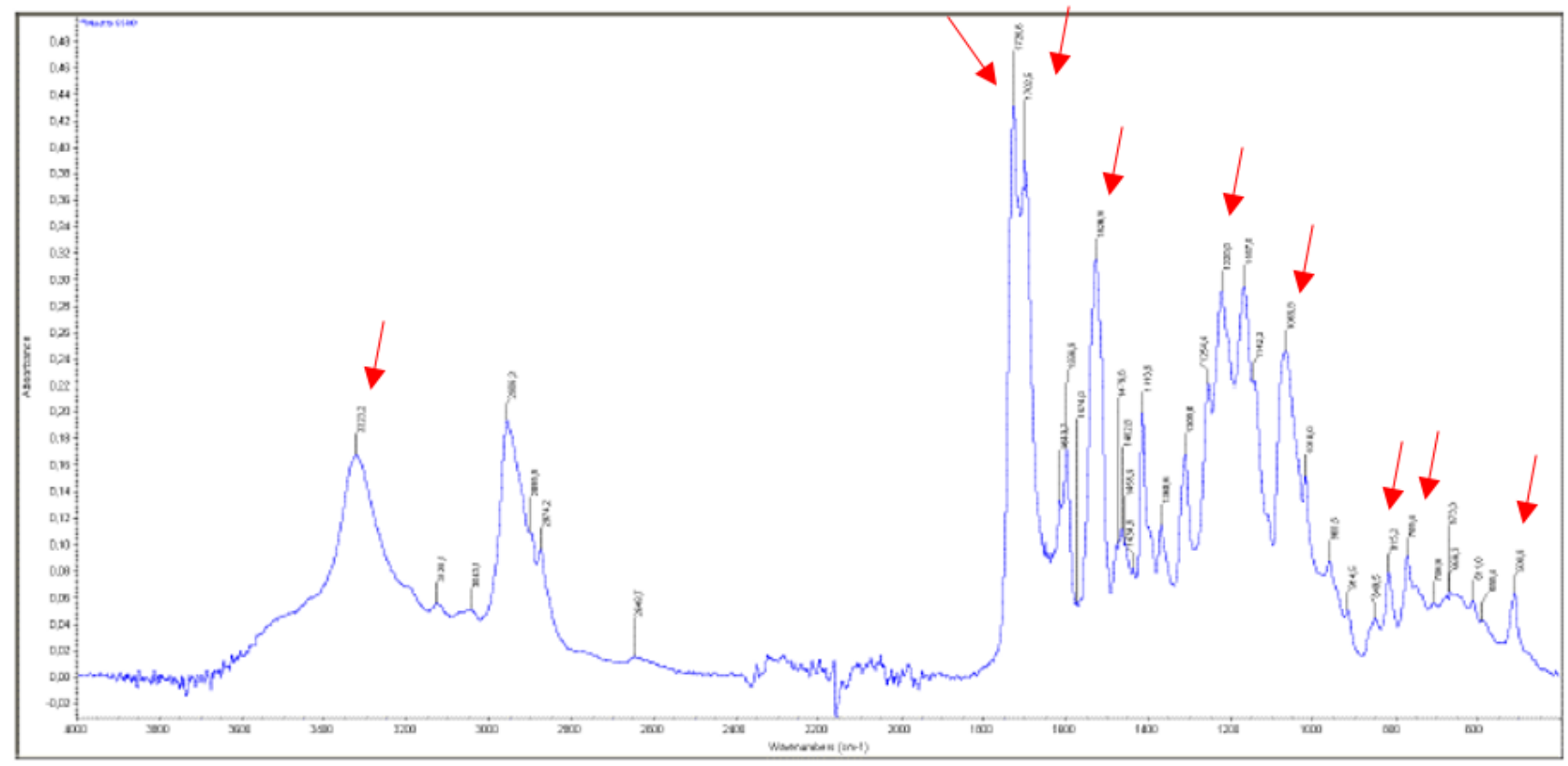

\section{Figure 6}

FTIR spectra representation of the presence of polyester (PEST) in the Odonata sample. The red arrows show the wavenumbers related with the polymeric read. 


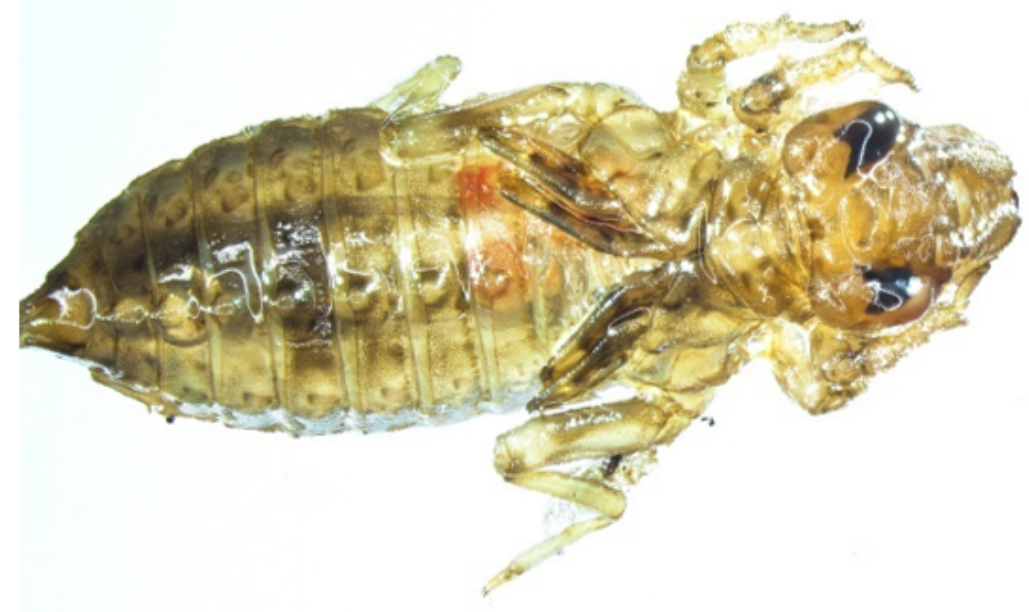

Figure 7

Gomphus, from the Gomphidae family. It has fragments of ethylene-vinyl- acetate and polyesterurethane incorporated inside its body. The microplastics were extracted using tweezers.
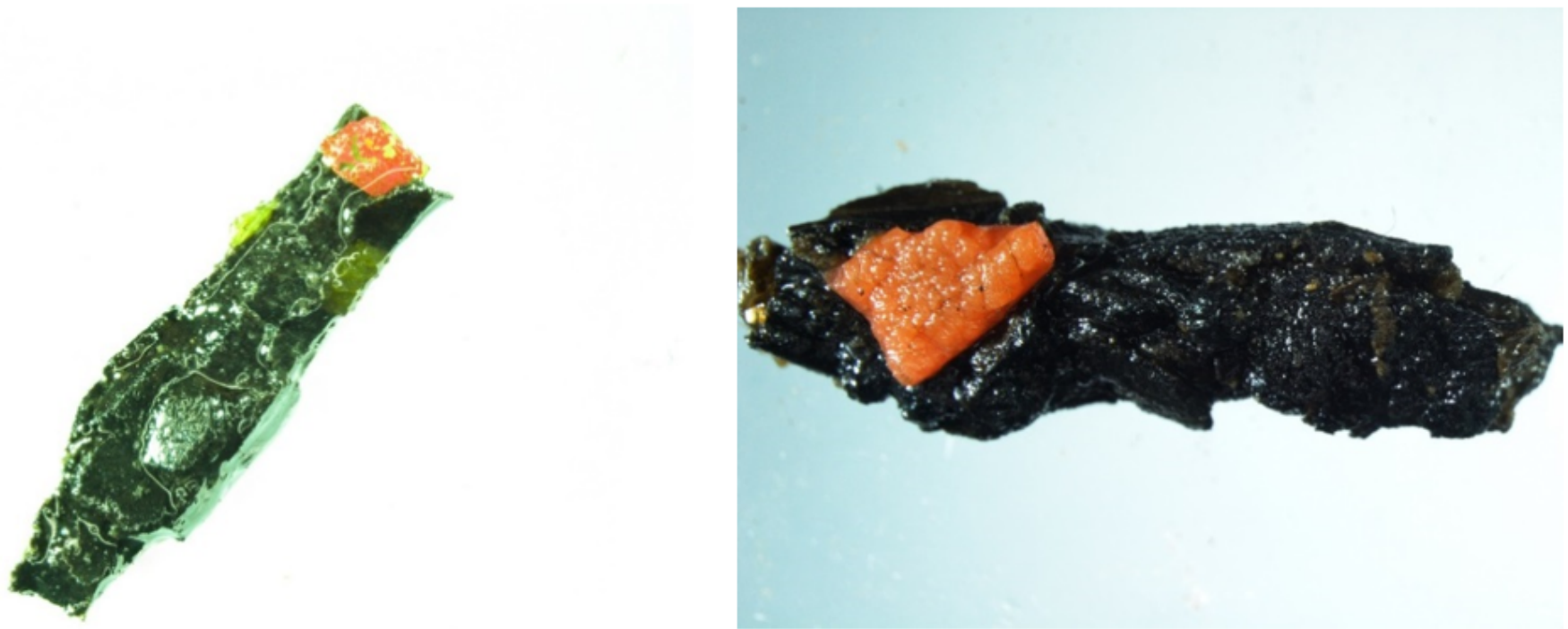

\section{Figure 8}

Two Trichoptera (Lepidostomatidae on the left and Limnephilidae on the right) cases that have incorporated fragments of polyethylene for their construction. 